The character of the impulse and sounds of the heart will generally enable us to make a diagnosis. The distinction is of great moment; for in the first case stimulants would of course be necessary, in the second sedative measures.

Local palsies of any motor or sensory nerve, or local neuralgiæ or convulsions, may occur, the affected nerves being either irritated or enfeebled.

If jaundice, co-existing with free bile flow, or any other secretion flux occur, it indicates that the vaso-motor nerves of the part are palsied, whence comes dilatation of blood-vessels, byperæmia, and over-activity of the gland tissue.

The formation of a splenic tumour results from excessive flow of blood to the part, and increased formation of splenic tissue, i.e. increased nutrition. It is therefore quite analogous to a gland flux. Both occurrences illustrate well the develop. ment of increased activity in the affected tissue as the result of paralysis of its vaso-motor nerves.

The common occurrence of dysentery, either primarily from exposure to malaria, or as a sequel or complication of malarious fever, is evidently a localisation of the morbid action, or it may be a concentration. The vaso-motor nerves of the large intestine are paralysed, and the usual results take place. It is to be mentioned, that the condition of a part, as to vital power, has much to do in determining the occurrence of inflammation after hyperæmia has been set up in the way supposed. If the vital power be tolerably sound, the part may remain unaltered, or may exhibit greater activity, as in the case of the gland flux; but, if the vital power be depressed, severe inflammation may result, e.g. purulent ophthalmia after section of the sympathetic in the neck. Though we can by no means see thoroughly into the matter, yet it does appear that there is a relation between the tissue power, the functional energy of a part, and its blood supply. In the healthy working of the apparatus, the former takes the initiative; and the byperæmic afflux is subordinate, and ministers to the calls of the tissue in its increased nutrition. In inflammatory disorder, the vital power, which can use the blood for normal purposes, is depressed, and the hyperæmic aftlux predominates, issuing in wasteful effusions of corpusculating fluids, mucus, or pus. Nay, it seems highly probable that in conditions of depressed vitality, as in frostbite the scorbutic dysentery of the Crimea and elsewhere, the existence of hyperæmia, even in moderate amount, acts as a morbid and destructive stimulus to the weakened part.

Having thus endeavoured to view some of the multifold manifestations of malarious disorder in the light of recent neuropathological research, it may be well to consider shortly what bearing these views have on other kinds of fever. It will be sufficient to take for examination two types, to one or other of which all approximate; viz., first, the severe inflammatory fever of tropical countries; second, the ordinary low fever, typhus, or typhoid, of our own. The phenomena of the first are, as described by Dr. Copland, slight chills only at the onset, subsequently "strong, full, hard, accelerated pulse", great heat, healache, and sometimes violent delirium, or maniacal excitement. Free venesection (to three or six pounds) is necessary. If in such fevers, on the above view, we admit the pyrexial condition to depend essentially on paralysis of the sympathetic, still it seems absolutely necessary to assume that the other tissues are in a state differing greatly from that which they manifest in many malarious, and all low fevers. The poison which has paralysed the sympathetic, has in no degree weakened the heart or the other organs. Hence the heated blood, acting on structures vigorous and prompt to respond to the stimulus, excites reactionary phenomena of great violence. It is the task of the physician to moderate these, as, if allowed to run their course unchecked, they induce a period of dangerous or fatal exhaustion.

How very apposite to this is all that we observe in the second type-the low fevers! Here every part alike bears the stamp of depression and debility. The sympathetic system is palsied, and hence the febrile heat, and the proneness to hyperæmia in various parts. The heart is enfeebled, and often needs stimulus to keep its action from failing; its very fibre often tends to soften and degenerate. The brain is enfeebled, and hence the low delirious wandering or the sopor. The voluntary muscles declare their atony by the down-sunk posture of the patient.

The lesson of this seems to be, that while we incline, as we may reasonably do, towards the theory of the nerve origin of pyrexial phenomena, we must not lose sight of the fact that the other corporeal systems are also affected to a greater or less degree by the fever poison, and that the event of the disease may in great measure depend on the amount of vital resistance and energy which they retain. In malarious fevers the nervous system (cerebro-spinal and sympathetic) is certainly far more affected than the others. In low fevers all the systems alike seem to be paralysed and depressed. In sthenic fevers no system, except the sympathetic, seems to have suffered depression, but perhaps to be rather in a state of abnormal irritability. Thus one physician may choose for his motto, " $\mathrm{He}$ fed fevers"; another, "He toned or soothed fevers"; a third, "He bled fevers"; each according to the kind he had most to deal with.

\section{DEFICIENCY OF FINGERS TRANSMITTED THROUGH SIX GENERATIONS.}

By Draper Mackinder, M.D., Gainsborough.

UNDER the title of "Hereditary Formations", a letter from $\mathrm{Mr}$. Willis, of Plumstead, appeared in the Lancet for Sep. 5th, wherein the writer mentions a repetition of an abnormal parental type through six generations. Believing with Mr. Willis that so decided a manifestation of a peculiarity in the progenitor is rarely extended through so many links in the descending family chain, I beg to forward, for the edification of the curious in such matters, an account of an equally interesting case, where there has been a deficiency instead of a redundancy of parts through several generations.

A Mrs. Thomas Chapman, of this town, on the 31st of March last, was attended in her confinement by my assistant, Mr. Capron. In consequence of an absence of certain useful members of the body, to be particularised hereafter, the mother was very naturally anxious to know if her babe had been modelled more in accordance with the Paradisian prototype than with her imperfectly sculptured self; and we can well imagine the parental joy on hearing that, to non-professional observers, her firstborn daughter would readily pass muster as a fair specimen of the daughters of England.

In the presence of Mr. Capron's successor, Mr. Smallman, and three generations of the family in question, I obtained the following particulars, which I will endearour to give in an intelligible form, tracing the generations backwards.

Generation I. The Infant. The middle phalanges of the eight fingers are wanting, the last phalanges articulating with the first, and giving a peculiar short and tapering appearance. The nails of both little fingers are absent, and that of the right ring finger is abortive. The toes are all nearly of the same length, and well suited for the square-toed boots.

Generation II. The Mother. The middle phalanges of eight fingers and all the nails are absent. The first phalanges articulate with the last, which are much shorter than common, and have the exact appearance of having undergone amputation at the middle of each third phalanx by a transverse flap. The fourth toe of each foot has only the first phalanx.

Mrs. Chapman is the youngest of a family of nine, the seven elder of whom and their children were of legitimate conformation.

Her brother, the eighth child, who was drowned at sea, had the ring and little fingers of both hands minus the second and third phalanges and nails; and the fourth and fifth toes of each foot were united by a web.

Generation III. The Grandfather possessed only the first phalanges of the eight fingers, the thumbs being flattened, and the phalangeal articulations very imperfect.

He had two brothers and ten sisters, of whom

One sister had the eight middle phalanges and the nails wanting.

A second sister had the third middle phalanges and nails wanting.

Another sister had the right index normal, and seven fingers minus the second and third phalanges and nails.

A brother had the same malformations as the last mentioned sister.

All the four had an irregularity about the toes. The other brother and sister were all riolht.

One of his brothers married, and had four daughters. The first was properly formed; the other three wanted the second phalanges and nails to all the fingers. Of the families of the other brother and his sisters nothing accurately is known.

Generation Iv. The Grandfather's Mother and three of his sisters, like himself, were all mimus the second and third phalanges and nails of eight fingers, and the second phalanges of the fourth toes.

Generation v. His Maternal Grandmother, and 
Generation vi. His Maternal Great Grandmother, had the same parts deficient as himself.

Generation vir. Her Mother was the soil which gave such vigorous root to the unfortunate weed.

There were other branches, but of the nature of their deviation from the regular form no reliable information is at hand.

Whatever may be the theory of learned physiologists and profound philosophers with reference to such "hereditary formations", their abstract speculations will at once be diffused into vapour by the rationale of the infant's grandmother. According to this venerable lady, the foolish patriarch of the six generations had in his garden a tree which bore a single apple. For this he entertained the most profound respect, and forbade any one to pluck it. In a weak and evil moment, beguiled by some unhallowed power, his spouse put forth her hand and stole the solitary prize. Mighty was the anger of her lord and master when he beheld the fruitless tree; and, in language unselect, he cursed the thief, and prayed, for so heinous an offence, that the fingers which touched the apple might all be chopped off. His wife, enceinte, feared much, and in solitude poured out her mournful regrets, but dared not confess the crime. Alas! time passed by; her hour of pain drew near; the fearful prayer, too truly, had been heard; 8 child was born; but, sad to tell, the fingers which its father had wished to be amputated had strangely forgotten to grow. Since the visitation of the sins of the fathers on the children to the third and fourth generation has been more than accomplished here, we will now hope that the full penalty of the misdeed has been paid, and this hereditary formation will henceforth be discussed as a thing witnessed in time past.

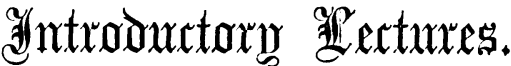

\section{GROSVENOR PLACE SCHOOL OF MEDICINE.}

The Introductory Lecture at this School was delivered by Dr. Rrchardson, who chose as his subject The Medical Pilgrim's Progress. After some preliminary remarks, the lecturer said that he had undertaken to point out the path of pilgrimage. $\mathrm{He}$ assumed that his hearers were anxious that the result of their journeyings should be true success; and they must start fairly, knowing the worst, and striving for the best. He then proceeded to sketch out two paths trodden by medical pilgrims; one a broad and easy path, and the other narrow and difficult, but the only true one. The broad and easy path is followed by many; among whom are the mean with means, waiting for something to turn up, and place them in positions which they cannot sustain-the "young ladies" in physic; those who try to advance by paying homage to the vanity of their superiorsthe "toadies"; and again, the drowsy, helpless, care-for-nothings, who drawl on, deriding a progress which they cannot followthe " old women". None of the auditors, the lecturer was sure, wished to rank as either of these. He would, then, enter with them on the difficult path, rendered sacred by the foot-prints which indented it-the way trodden by Hippocrates, Vesalius, Harvey, and Hunter. In this path every one must walk who would follow the medical pilgrim's progress to its ultimate greatness. Let no one fear the labour. It is not genius which is required; it is the combination of force, fearlessness, and fact. These are inherent in man; and he who cultivates them persistently will be the representative of genius. Dr. Richardson then went on to show the importance of physical as well as mental training. One maxim, important to be followed, was, "live abstemiously"; and the labours of Franklin and Morgagni were adduced as proofs of what can be thus done. He then proceeded:-

"Connected with the physical training of the body, I recom. mend to you strongly the continued and systematic strengthen. ing of the muscular power. Our profession lending itself too readily to the old wife's stereotype of a doctor, makes a grand and universal mistake in this respect. A doctor may pipe a sentimental song in an elegant carbonic acid depót called a drawing-room. Yes; that is allowable: but a hearty laugh, the most healthy exercise in nature, is forbidden in prim society. The doctor may play a rubber at whist, with a whining old maid for a partner; that is excusable, unavoidable sometimes He may mildly go through a dance, but he must not romp or polka : certainly not. He may drink wine after dinner till his head swims - that is essential. He may, in fact, do everything of the kind that is effeminate and enervating: but heaven protect the man if he ventures to play tennis, cricket, or any other game that shall call into unwonted play his elegant, half-useless, mute-at-a-funeral clad limbs.

"Gentlemen, without encouraging you to any injurious pursuits, I call upon you, as the coming representatives of medicine, to disobey the old woman oracle who dictates these absurd conventionalities. Innocent active pleasures are the salt of life; and the more vigorous the man, the more vigorous the mind. I take it that much of the namby-pambyism, vapidity, and anæmic conceit, which too much characterise all the learned professions, are due to this slow process of effemination, this undermining of the soul. Go to the British Association for the Advancement of Science-that parliament of intellectand observe those who are the science.Hercules. You will find them amongst the men who are most genial, best body-built, least conventional."

Proceeding then to the mental labour of the medical pilgrim, the lecturer took occasion to observe that the science and practice of medicine is passing through a silent but rapid revolution. And this transition belongs to all things human.

The lecturer then went on to show how the student must keep up with the progress of medical knowledge-not by books, but by a natural course of study of objects. For this, in every department of medical science, there is every facility.

"Need I say-yes, I must say-that there is no excuse, either in morals or in knowledge, for that student of medicine who, in these days, is content to take his knowledge of natural things from pastors and masters, when he might take it from the Great Master over all. It is the worship of idols, such work, in the presence of the God of the universe.

"Thus it is that I warn you to go always to the originals for your information, and both now and hereafter to be very suspicious about other authorities. And, while you are thus yourselves learners from the realities of science, take care, as you advance into intellectual manhood, not to mislead others, by constituting yourselves the authorities of Nature. Gentlemen, believe me, there is not a greater quack extant, than he who claims for himself, and sticks himself up to, this distinction. There can be but ons authority in science. It is true, a man may discover a natural law or fact, and make it known; but, in the very acts of his discovery and publication, he resigns all claims to authority, by calling, as he does, on every passer by to see the fact for himself. Such a man is the greatest of men but he would as soon claim to himself the authorship of the natural fact itself, as of its mode of operation."

Dr. Richardson then went on to deprecate a reliance on the many so-called "authorities" to be found in the broad and easy way of medicine: "members of a Cockney family, who, walking to the foot of Ben Lomond, pump the guide with note-book in hand, straightway return home satisfied with their intimate knowledge of the mountain, and write an authority-description of the prospect from the mountain summit."

Dr. Pichardson then went on to point out, since it was neces. sary to follow the changes in medical science, how the steps of the modern student should be directed differently from those of the ancients. He contrasted with the old method (not now thoroughly expunged) of arriving at general laws by the enumeration of all particulars, the true Baconian method of induction by exclusion. In past time, he was thought greatest who could most elaborately split up symptoms into diseases per se. Now, men are advancing by true induction back from symptoms to causes-and to few causes. In olden time, the manifestations of disease were held to originate in the body itself : now, we have traced the causes of diseases out of the body, and have proved that ninety-nine out of a hundred maladies are from the external world. And, in accordance with this change in the views regarding the origin of disease, has been the change in treatment-in some instances carried to an extreme. In the treatment of disease according to modern knowledge, there are three things to be learnt:-1. How to remove external causes; 2 . How far to trust to the spontaneous evolution or removal of causes which have taken effect on the body; 3. How to meet those extreme results which sometimes succeed the natural or spontaneous attempts at removal. In studying the action of medicines, the student must learn to isolate the results produced by medicaments from those which would fol. low naturally, were no medicaments used at all. Practitioners vary in their practice ; and each thinks himself the most successful. Hence the success is dependent on external or internal natural agencies, not universally seen nor comprehended. The 